\title{
Change Detection of Lakes in Pokhara, Nepal Using Landsat Data ${ }^{\dagger}$
}

\author{
Tri Dev Acharya ${ }^{1}$, In Tae Yang ${ }^{1}$, Anoj Subedi ${ }^{2}$ and Dong Ha Lee 1,* \\ 1 Department of Civil Engineering, Kangwon National University, Chuncheon 24341, Korea; \\ tridevacharya@gmail.com (T.D.A.); intae@kangwon.ac.kr (I.T.Y.) \\ 2 Institute of Forestry, Pokhara Campus, Tribhuvan University, Pokhara 33700, Nepal; \\ anojsubedi99@gmail.com (A.S.) \\ * Correspondence: geodesy@kangwon.ac.kr; Tel.: +82-33-250-6232 \\ + Presented at the 3rd International Electronic Conference on Sensors and Applications, \\ 15-30 November 2016; Available online: https://sciforum.net/conference/ecsa-3.
}

Published: 14 November 2016

\begin{abstract}
Pokhara, city of lakes, is second largest and most beautiful tourist place in Nepal. Out of seven lakes, the large three: Phewa, Begnas and Rupa are famous for tourist attraction, whereas the rest are small and less known. Lakes are not only economic value, but are also ecological and environmental resources. But, these lakes are facing challenges due to climatic and anthropogenic activities. As these changes are slow and takes long time, the damage unnoticed to take measures. Hence, long historic data provided such as of remote sensors are concrete evidence of change, which help us understand the cause and prevent further change. Landsat series provide the continuous data with high temporal resolution freely to the scientific community. For such data, many simple and low cost index methods has been developed to identify water bodies. In this study, we use these indices to detect the change of lakes in Pokhara city using Landsat data of 25 years gap i.e., 1988-2013. Normalized Difference Vegetation Index (NDVI), Normalized Difference Water Index (NDWI), and Modified NDWI (MNDWI) were investigated for the unsupervised extraction of surface water from Landsat data. A model is developed in ArcGIS by differencing the water bodies derived form index methods and difference were calculated for positive and negative change. The results show that the area of Phewa has shrunken, whereas Rupa being increase in surface water area. Began has few changes and other small lakes except Dipang lake, were not detected. Dipang Lake showed increase in surface water area after 25 years of gap. The result can be helpful in reclaiming and restoration of lake area, preserve and maintain the wetland ecosystem in the city. Also, the model presented in the manuscript can be used for change detection of surface water due to flood, or debris blockages in disaster prone countries.
\end{abstract}

Keywords: Pokhara; Nepal; seven lakes; Landsat; water index; change detection

\section{Introduction}

The Pokhara, city of lakes, is second largest and most beautiful tourist place in Nepal. Out of seven lakes, the large three: Phew, Begnas and Rupa are famous for tourist attraction, whereas the rest are small and less known. These lakes not only provides fresh water for agriculture and aquatic products and attract tourists but also plays equally important role in terms of natural water cycle, climatic regulation, ecological and environmental balance [1]. But, these lakes are facing challenges due to climatic and anthropogenic activities. As these changes are slow and takes long time, the damage unnoticed to take measures. Hence, long historic data provided provide concrete evidence of change, which help us understand the cause and prevent further change. 
Series of optical remotes sensors such as KOMPSAT, Landsat, SPOT, and Worldview etc. are continuously observing and capturing the earth surface since last four decades. They provide low-cost and reliable information for environmental changes, with their long collected repeatable and even real-time data [2,3]. Due to availability of free continuous optical remote-sensing images of high temporal resolution to the scientific community, Landsat series are the most common optical remote sensors for mapping of waterbodies [3-5].

Many studies has proved their importance in detecting change of landcover/landuse as a whole or any particular interest such as farmland, forest, urban and water. Surface water is one of the most precious resources in Earth, and it changes in time and space as a consequence of climate change, land-cover change, and other environmental changes. Remote Sensing has been used for the dynamic monitoring of lake and other water resources, flood detection, change detection of reservoir conditions, and large-scale surface water monitoring based on surface water detection.

Numerous water extraction algorithms for optical remote-sensing images have been developed, and they can be categorized into four types: (a) thematic classification, including both supervised and unsupervised methods [6-8]; (b) spectral unmixing [9]; (c) single-band thresholding [10]; and $(\mathrm{d})$ spectral water index methods [11-15].

Among these methods, unsupervised methods (refer to the techniques that do not require the user to specify any information about the features contained in the images), including the spectral water index methods, are the most commonly used waterbody extraction methods. This is due to the ease of use, low computational cost, and the fact that less human knowledge is needed. These methods have achieved extremely good results with Landsat images [16]. McFeeters proposed Normalized Difference Water Index (NDWI) using spectral reflectance of water sensitive Near-Infrared (NIR) and Shortwave-Infrared (SWIR) band [15]. Xu developed a modified NDWI (MNDWI) in which the middle infrared (MIR) band which replaced the near infrared (NIR) band in order to decrease false positive from built-up lands [13]. The threshold adopted for these indices to spectate water and background classes are usually set to zero. Also for better adjustment of threshold according to the index map, Otsu threshold are also used. Malahlela [17] formulated Simple Water Index (SWI) which requires no threshold such that vegetation pixels with negative values are suppressed automatically (nullified). Xie explored unsupervised inland water extraction based on the new Landsat 8 Operational Land Imager (OLI) imagery [18].

In this study, we use the water indices to detect the change of lakes in Pokhara city using Landsat data of 25 years gap. A model is developed in ArcGIS by differencing the water bodies derived form index methods and the difference was calculated for positive and negative change. One vegetation indices Normalized Difference Vegetation Index (NDVI) and other two water indexes Normalized Difference Water Index (NDWI) and Modified Normalized Difference Water Index (MNDWI) were used for the change detection.

\section{Experiments}

\subsection{Test Site}

A geographical area bounded between latitude $28^{\circ} 08^{\prime} 2.56^{\prime \prime} \mathrm{N}$ to $28^{\circ} 15^{\prime} 9.85^{\prime \prime} \mathrm{N}$ and longitude $83^{\circ} 54^{\prime} 30.20^{\prime \prime} \mathrm{E}$ to $84^{\circ} 8^{\prime} 18.57^{\prime \prime} \mathrm{E}$ is selected as the study area. The area bounds seven lakes that are situated in the Pokhara city. Figure 1 shows the location map of all seven lakes in Pokhara.

Among the lakes, Phewa, Begnas are large in area, Rupa being medium and rest are small and alomost are in the position to dry and extinct. The source of the water in these lakes is form monsoon rain and the seepage form the surrounding mountains. The large lakes are more popular for as the tourist spot and many commercial activates happens around them, whereas the smaller lakes are surrounded by farmlands and are almost filled up.

\subsection{Data}

The Level 1 Terrain Corrected (L1T) data acquired by Landsat series of data available form USGS GLOVIS portal were used as the data in the study. Two images from form 1988 and 2013, a 25 years 
gap data were used for the detection of change in the surface water of the lakes inside study area. The data were chosen were such that both are from same season to maintain uniformity in conditions. The details of the image are given in Table 1.

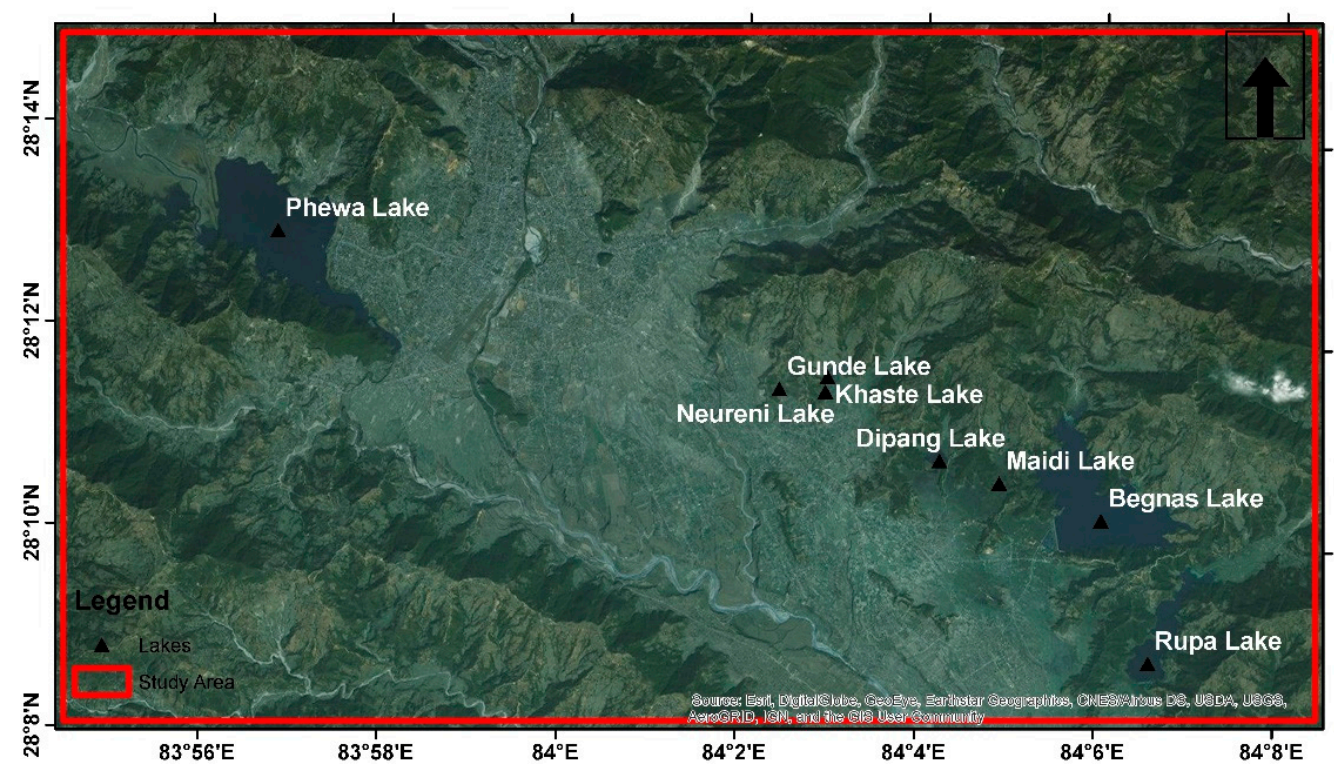

Figure 1. The geographical locations of Lakes located in Pokhara city, Nepal.

Table 1. Specification of Landsat TM, and OLI data used in the study.

\begin{tabular}{|c|c|c|c|c|c|}
\hline Satellite & Sensor & Path/Row & Year & Resolution & Wavelength \\
\hline \multirow{6}{*}{ Landsat 5} & \multirow{6}{*}{ TM } & \multirow{14}{*}{$142 / 40$} & \multirow{6}{*}{1988} & \multirow{14}{*}{30} & Band 1: 0.45-0.52 \\
\hline & & & & & Band 2: 0.52-0.60 \\
\hline & & & & & Band 3: 0.63-0.69 \\
\hline & & & & & Band 4: 0.76-0.90 \\
\hline & & & & & Band 5: 1.55-1.75 \\
\hline & & & & & Band 7: 2.08-2.35 \\
\hline \multirow{8}{*}{ Landsat 8} & \multirow{8}{*}{ OLI } & & \multirow{8}{*}{2013} & & Band 1: $0.435-0.451$ \\
\hline & & & & & Band 2: $0.452-0.512$ \\
\hline & & & & & Band 3: 0.533-0.590 \\
\hline & & & & & Band 4: $0.636-0.673$ \\
\hline & & & & & Band 5: 0.851-0.879 \\
\hline & & & & & Band 6: 1.566-1.651 \\
\hline & & & & & Band 7: 2.107-2.294 \\
\hline & & & & & Band 9: 1.363-1.384 \\
\hline
\end{tabular}

\subsection{Method}

In Environment for Visualizing Images (ENVI) software, as a pre-processing step, radiometric calibration was performed and thus converting the digital numbers into at-satellite reflectance. The sub-images containing the lakes area were extracted using the Area of Interest tool in ENVI for economic data size and processing time. Images pre-georeferenced to Universal Transverse Mercator zone 45 North projection using WGS-84 datum were exported into Geographic Tagged Image File Format (GeoTIFF) for further analysis.

After pre-processing, both of the images were used to calculate NDVI, NDWI, and MNDWI indices according to Table 2, which were then reclassified based on zero threshold for water and nonwater. One date index were given positive one and other as negative one value so that on adding them the change could be detected as increase or decrease in surface area. Whereas the zero will indicate no change with time. A model was developed in ArcGIS for the unsupervised change detection as shown in Figure 2. 
Table 2. Formulae of spectral Indices applied in the study area.

\begin{tabular}{cccc}
\hline S. No. & Spectral Indices & Formula & Reference \\
\hline 1 & Normalized Difference Vegetation Index (NDVI) & (NIR - Red)/(NIR + Red) & {$[19]$} \\
2 & Normalized Difference Water Index (NDWI) & $($ Green - NIR)/(Green + NIR) & {$[15]$} \\
3 & Modified Normalized Difference Water Index (MNDWI) & $($ Green - SWIR)/(Green + SWIR) & {$[13]$} \\
\hline
\end{tabular}

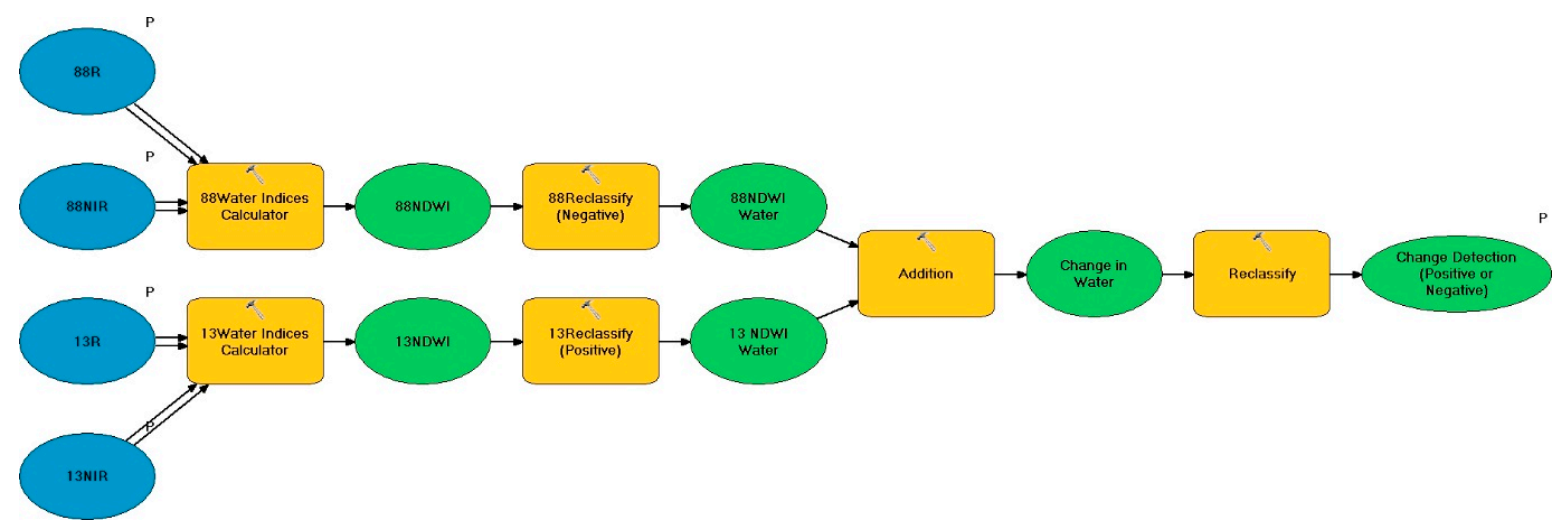

Figure 2. ArcGIS model for unsupervised change detection based on NDWI.

\section{Results and Discussion}

In order to detect the surface area changes of the lakes in the period 1988-2013, the water surface of each lake in each temporal image was extracted using the four indices methods. The change detected were classified such that it represent the surface water change in positive and negative. Figure 3 shows the resulted changes in the lakes for all the methods.

The resulting maps show that the area of Phewa has shrunken, whereas Rupa being increase in surface water area. Began had few changes. While deriving the water indices, the smaller lakes such as Gunde, Khaste, Neureni and Madi, except Dipang were not detected in the process due to smaller size of surface water than the spatial resolution of Landsat images. Hence, the change in these lakes were not being able to calculate from mid resolution satellites. Dipang Lake showed increase in surface water area after 25 years of gap.

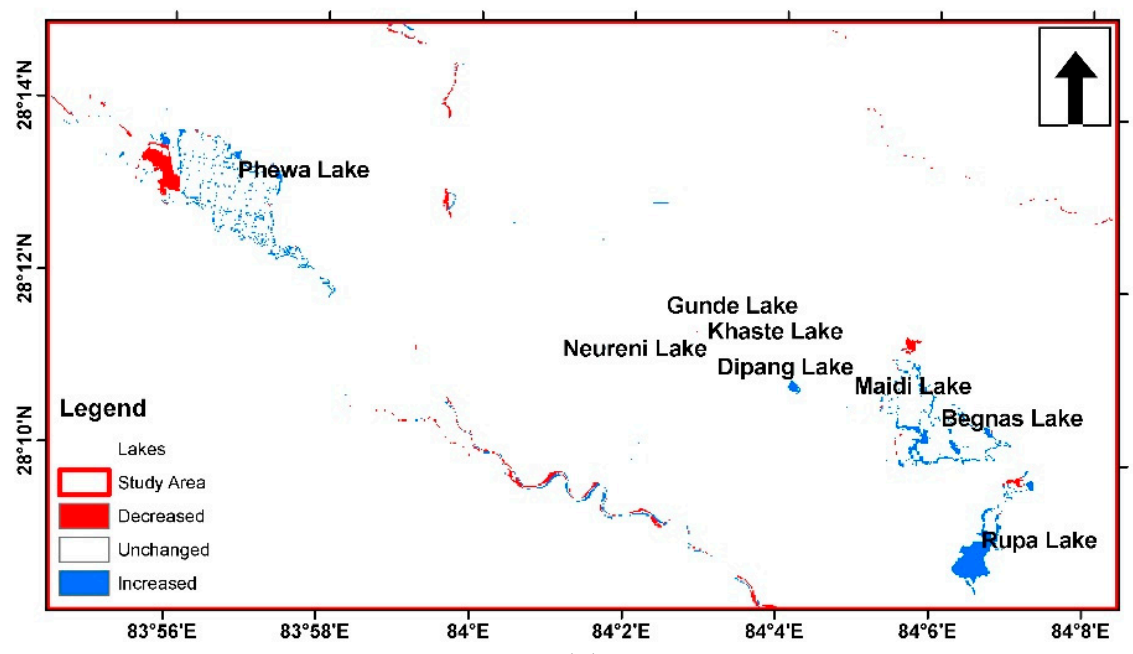

(a)

Figure 3. Cont. 


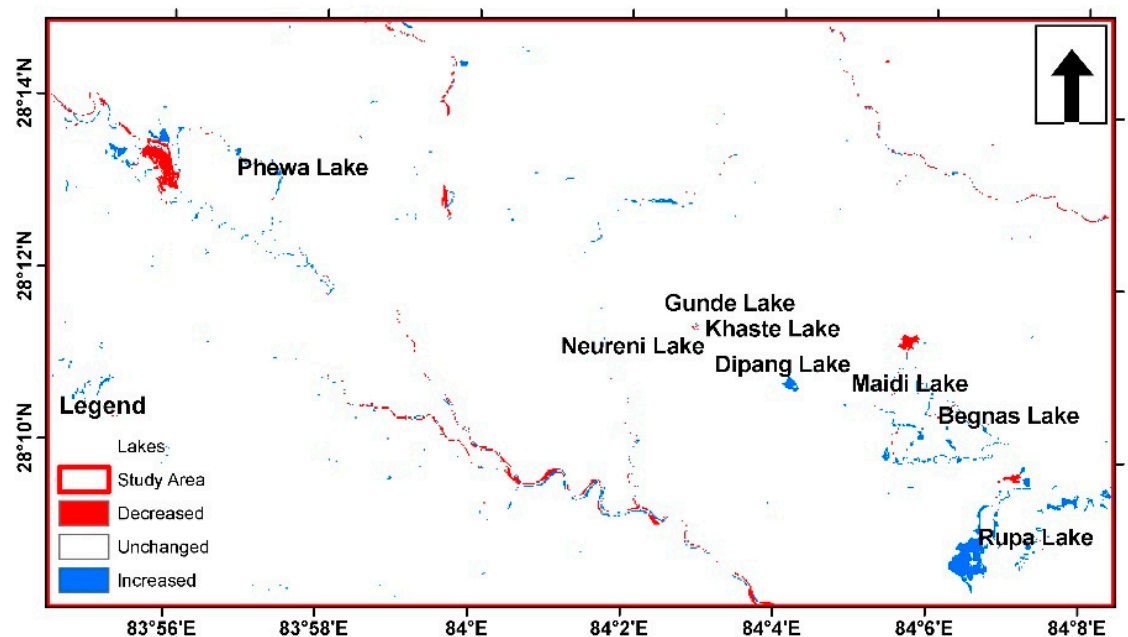

(b)

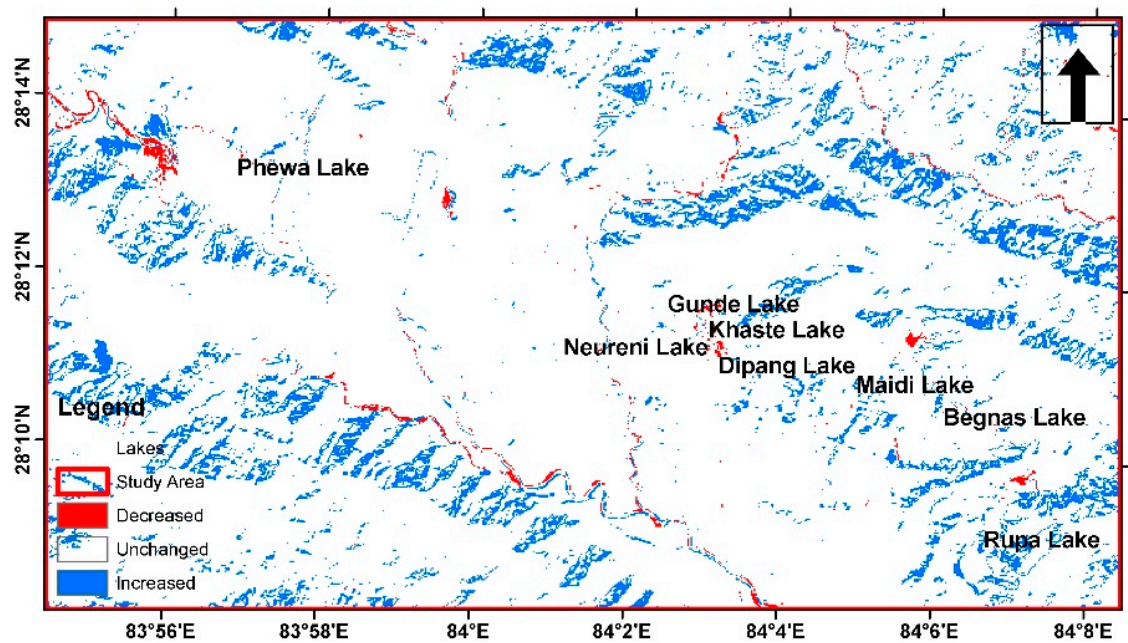

(c)

Figure 3. Results of change detection: (a) NDVI; (b) NDWI; and (c) MNDWI.

Regarding the performance of the unsupervised index method with zero threshold, it can be clear that the NDVI and NDWI shows good change effects than MNDWI along with other water bodes such as river and ponds. In NDVI, the dark pixels has been misclassified and the increase effect has been shown in Phewa Lake. Similarly, the MNDWI misinterpreted the change and showed increase in water along with shadows of the hilly regions as well. The effect in the NDVI and MNDWI might be due to imperfect threshold. In such cases, Otsu thresholds to get better binary thresholding could be useful.

\section{Conclusions}

In this study, unsupervised index methods were used to detect the change of lakes in Pokhara city using Landsat data of 25 years gap. After pre-processing, automatic model was made in the ArcGIS for calculating the positive and negative change in the surface water of the lakes. Result shows better change detection using NDWI, then NDVI and not good with MNDWI. Large lakes Phewa and Begnas shows shrinking whereas Rupa showed increase in surface water.

For smaller lakes, mid resolution Landsat image pixels were unable to detect the water whereas for larger ones, they were successful. The result can be very useful in countries like Nepal where areas cannot be field visited are difficult or the area of water related disasters like flood or debris dam. Similar methodology can be adopted to other specific interest based on the suitable detection indices such as built-up area, agriculture. 
Author Contributions: Tri Dev Acharya performed and prepared this research article. Anoj Subedi carried out the processing, field work and manuscript preparation. In Tae Yang and Dong Ha Lee supervised and helped in manuscript writing and final submission.

Conflicts of Interest: The authors declare no conflict of interest.

\section{References}

1. Li, L.; Xia, H.; Li, Z.; Zhang, Z. Temporal-Spatial Evolution Analysis of Lake Size-Distribution in the Middle and Lower Yangtze River Basin using Landsat Imagery Data. Remote Sens. 2015, 7, 10364-10384.

2. Jiang, H.; Feng, M.; Zhu, Y.; Lu, N.; Huang, J.; Xiao, T. An Automated Method for Extracting Rivers and Lakes from Landsat Imagery. Remote Sens. 2014, 6, 5067-5089.

3. Rokni, K.; Ahmad, A.; Selamat, A.; Hazini, S. Water Feature Extraction and Change Detection Using Multitemporal Landsat Imagery. Remote Sens. 2014, 6, 4173-4189.

4. Acharya, T.D.; Lee, D.H.; Yang, I.T.; Lee, J.K. Identification of Water Bodies in a Landsat 8 OLI Image Using a J48 Decision Tree. Sensors 2016, 16, 1075.

5. Frazier, P.S.; Page, K.J. Water Body Detection and Delineation with Landsat TM Data. Photogramm. Eng. Remote Sens. 2000, 66, 1461-1468.

6. Tulbure, M.G.; Broich, M.; Stehman, S.V.; Kommareddy, A. Surface Water Extent Dynamics from Three Decades of Seasonally Continuous Landsat Time Series at Subcontinental Scale in a Semi-Arid Region. Remote Sens. Environ. 2016, 178, 142-157.

7. Sivanpillai, R.; Miller, S.N. Improvements in Mapping Water Bodies Using ASTER Data. Ecol. Inform. 2010, 5, 73-78.

8. McIver, D.K.; Friedl, M.A. Using Prior Probabilities in Decision-Tree Classification of Remotely Sensed Data. Remote Sens. Environ. 2002, 81, 253-261.

9. Sethre, P.R.; Rundquist, B.C.; Todhunter, P.E. Remote Detection of Prairie Pothole Ponds in the Devils Lake Basin, North Dakota. GISci. Remote Sens. 2005, 42, 277-296.

10. Du, Z.; Linghu, B.; Ling, F.; Li, W.; Tian, W.; Wang, H.; Gui, Y.; Sun, B.; Zhang, X. Estimating Surface Water Area Changes Using Time-Series Landsat Data in the Qingjiang River Basin, China. J. Appl. Remote Sens. 2012, 6, 063609.

11. Feyisa, G.L.; Meilby, H.; Fensholt, R.; Proud, S.R. Automated Water Extraction Index: A New Technique for Surface Water Mapping using Landsat Imagery. Remote Sens. Environ. 2014, 140, 23-35.

12. Ji, L.; Zhang, L.; Wylie, B. Analysis of Dynamic Thresholds for the Normalized Difference Water Index. Photogramm. Eng. Remote Sens. 2009, 75, 1307-1317.

13. $\mathrm{Xu}, \mathrm{H}$. Modification of Normalised Difference Water Index (NDWI) to Enhance Open Water Features in Remotely Sensed Imagery. Int. J. Remote Sens. 2006, 27, 3025-3033.

14. Rogers, A.S.; Kearney, M.S. Reducing Signature Variability in Unmixing Coastal Marsh Thematic Mapper Scenes Using Spectral Indices. Int. J. Remote Sens. 2004, 25, 2317-2335.

15. McFeeters, S.K. The use of the Normalized Difference Water Index (NDWI) in the Delineation of Open Water Features. Int. J. Remote Sens. 1996, 17, 1425-1432.

16. Tulbure, M.G.; Broich, M. Spatiotemporal Dynamic of Surface Water Bodies using Landsat Time-Series Data from 1999 to 2011. ISPRS J. Photogramm. Remote Sens. 2013, 79, 44-52.

17. Malahlela, O.E. Inland Waterbody Mapping: Towards Improving Discrimination and Extraction of Inland Surface Water Features. Int. J. Remote Sens. 2016, 37, 4574-4589.

18. Xie, H.; Luo, X.; Xu, X.; Pan, H.; Tong, X. Evaluation of Landsat 8 OLI Imagery for Unsupervised Inland Water Extraction. Int. J. Remote Sens. 2016, 37, 1826-1844.

19. Rouse, J., Jr.; Haas, R.; Schell, J.; Deering, D. Monitoring Vegetation Systems in the Great Plains with ERTS. NASA Spec. Publ. 1974, 351, 309-317.

(C) 2016 by the authors. Licensee MDPI, Basel, Switzerland. This article is an open access article distributed under the terms and conditions of the Creative Commons Attribution (CC BY) license (http://creativecommons.org/licenses/by/4.0/). 